\title{
Hot Deformation Behavior and Microstructural Evolution of Twin-Roll-Casting Mg Alloy during High-Temperature Compression
}

\author{
Qingshan Yang $\mathbb{D},{ }^{1,2}$ Jiahong Dai, ${ }^{3}$ Sensen Chai, ${ }^{1}$ Daliang Yu, ${ }^{1}$ Bin Jiang, ${ }^{2}$ and Fusheng Pan ${ }^{2}$ \\ ${ }^{1}$ School of Metallurgy and Material Engineering, Chongqing University of Science and Technology, Chongqing 401331, China \\ ${ }^{2}$ National Engineering Research Center for Magnesium Alloy, Chongqing University, Chongqing 400044, China \\ ${ }^{3}$ College of Materials Science and Engineering, Yangtze Normal University, Chongqing 408100, China
}

Correspondence should be addressed to Qingshan Yang; qsyang@cqu.edu.cn

Received 18 July 2019; Accepted 27 November 2019; Published 18 December 2019

Guest Editor: Benjamin I. Imasogie

Copyright (c) 2019 Qingshan Yang et al. This is an open access article distributed under the Creative Commons Attribution License, which permits unrestricted use, distribution, and reproduction in any medium, provided the original work is properly cited.

\begin{abstract}
The deformation behavior and microstructural evolution of twin-roll-casting AZ31 Mg alloy sheets were investigated via hot compression tests at $0^{\circ}, 5^{\circ}$, and $10^{\circ}$ from the normal direction. Compression strains of $5 \%, 15 \%, 25 \%$, and $35 \%$ were employed at high temperatures of $450^{\circ} \mathrm{C}$ and $500^{\circ} \mathrm{C}$. The flow stress as well as the difference in the flow stress associated with different sampling directions decreased when the temperature was increased. Furthermore, the volume fraction of dynamically recrystallized grains increased with increasing deformation, whereas the average grain size decreased. The DRX grain size and the volume fraction of dynamically recrystallized grains increased with increasing deformation temperature. During ultrahigh temperature compression, the effect of sampling direction on the compression microstructure is relatively small.
\end{abstract}

\section{Introduction}

Magnesium (Mg) alloys, as the lightest structural alloys, have received increasing attention and have been extensively applied in various transportation systems [1-3]. However, the inherently poor workability of these alloys hinders their use in further engineering applications, owing mainly to the limited number of slip systems operating at room temperature [4-6]. Thus, the automotive applications of Mg alloys are limited mainly to die castings. Wrought products such as sheet and bar have been developed with the aim of broadening the application range of these alloys. In addition, the sheet should be readily formable into complex shapes. $\mathrm{Mg}$ alloys are more workable at elevated temperatures than at room temperature, owing to the activation of slip systems other than the basal slip system [7-9]. Hence, the hot forming of $\mathrm{Mg}$ alloys has been extensively explored.

The formability of $\mathrm{Mg}$ alloys can be increased through different fabrication processes, which mainly rely on the hot deformation methods. Mg-Al-Zn alloy, as the most widely used $\mathrm{Mg}$ alloys, has been extensively studied. Previous studies have shown that $\mathrm{Mg}$ alloys might undergo dynamic recrystallization (DRX) during hot working processes. J. C. Tan and M. J. Tan [10] evaluated the dominance of continuous recrystallization phenomena in the AZ31 alloy exposed to temperatures of $250-400^{\circ} \mathrm{C}$. They reported that due to the rapid grain growth, negligible grain refinement occurs during high-temperature DRX. Maximum grain refinement occurred at medium temperatures. Sitdikov and Kaibyshev suggested a temperature- and strain-dependency regime for the grain size variation [11]. Barnett reported that the dynamically recrystallized grains of $\mathrm{Mg}$ alloys are less sensitive to deformation conditions than those of other metals [12].

A twin-roll-casting (TRC) process combines casting and hot rolling into a single process, which would provide a means of producing $\mathrm{Mg}$ strip products at competitive costs for commercial applications $[13,14]$. However, reported studies of the associated twin-roll-casting and hot compression (HC) 


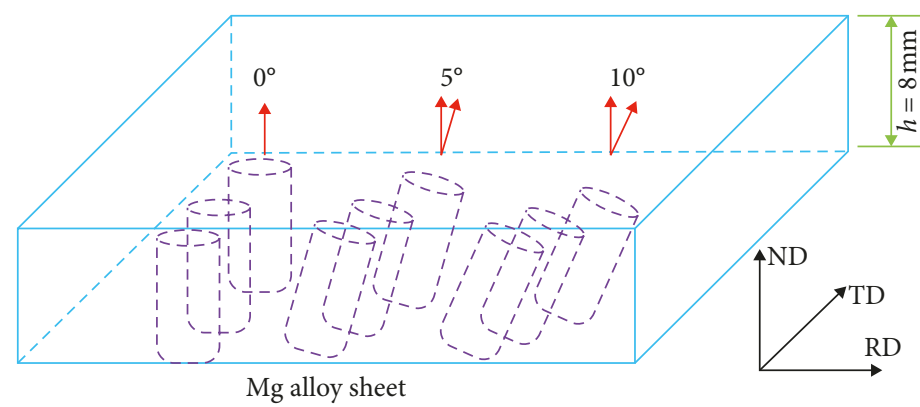

(a)

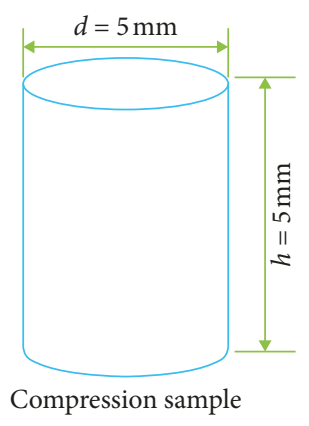

(b)

Figure 1: (a) Schematic showing the sampling directions. (b) Size of samples subjected to high-temperature compression.

processing of $\mathrm{Mg}$ alloys are rare. Therefore, in this work, the hot deformation behavior and microstructural evolution of twinroll-cast AZ31 alloy were investigated via hot compression at $450^{\circ} \mathrm{C}$ and $500^{\circ} \mathrm{C}$. The effect of different original sampling directions and different accumulated plastic deformations on the high-temperature deformation mechanism of the alloy was explored.

\section{Experimental Procedure}

An 8-mm-thick twin-roll-casting (TRC) AZ31 alloy (Mg-3 Al-1 Zn, in wt.\%) was investigated in this work. Cylindrical hot compression testing specimens were machined to a size of $\Phi 5 \times H 5 \mathrm{~mm}$. In preparation for the compression tests, cylindrical samples were cut from the TRC-AZ31 sheet at $0^{\circ}, 5^{\circ}$, and $10^{\circ}$ to the normal direction (ND), as shown in Figure 1.

To investigate the effects of high temperatures and accumulated plastic deformation, isothermal hot compression tests were performed at $450^{\circ} \mathrm{C}$ and $500^{\circ} \mathrm{C}$ for deformations ranging from $5 \%$ to $35 \%$ in steps of $10 \%$. During the tests, specimens were heated (heating rate: $10^{\circ} \mathrm{C} / \mathrm{s}$ ) to the deformation temperature and held isothermally for $240 \mathrm{~s}$. The specimens were then subjected to a hot compression test (strain rate: $0.15 \mathrm{~s}^{-1}$ ) on a Gleeble1500D machine. After hot deformation, the samples were water cooled to obtain the deformed microstructures.

After quenching in water, the deformed specimens were sectioned in the center parallel to the compression axis, and the microstructure was observed via optical microscopy (OM). To further investigate the occurrence of dynamic recrystallization (DRX) during high-temperature compression, the microstructures were examined after various deformation strains. The volume fraction of dynamically recrystallized grains was determined through a point counting technique. The DRX grains were almost readily distinguishable from the pre-existing grains, and the corresponding grain size was determined using an imaging analysis system.

\section{Results and Discussion}

3.1. Flow Stress Behavior. Figure 2 shows the true stressstrain curves for different deformations ranging from $5 \%$ to $35 \%$ under a strain rate of $0.15 \mathrm{~s}^{-1}$ at $450^{\circ} \mathrm{C}$. No steady state was observed for the $0^{\circ}$ and $5^{\circ}$ samples subjected to a low deformation of 5\%. A flow-stress steady state was observed when the deformation increased to $15 \%, 25 \%$, and $35 \%$. Most samples exhibited an almost steady-state flow behavior, and work hardening was restricted to very small strains $(<0.05)$ followed by mild flow softening, leading to a steady-state flow. The temperature-dependent flow behavior observed for $\mathrm{Mg}$ alloys was attributed to the activation of nonbasal slip systems at elevated temperatures. Chapuis and Liu reported that increasing the plastic deformation temperature of $\mathrm{Mg}$ alloys can result in high strain rate sensitivity, and secondary slip modes can be easily activated [15]. The true stress values of TRC-AZ31 with different sampling directions and different accumulated plastic deformations during the steady stage at $450^{\circ} \mathrm{C}$ are listed in Table 1. For the same deformation, the steadystate stress increased with the sampling direction. The difference in the flow stress associated with different sampling directions is attributed to the grain orientation of the twin-roll-cast AZ31 sheet alloy. Furthermore, the variation in the steady-state stress between different sampling directions decreased with increasing deformation, from $6 \mathrm{MPa}$ at $15 \%$ deformation to $2 \mathrm{MPa}$ at $35 \%$ deformation. Therefore, large strain and more complete recrystallization induced by hot deformation can improve the anisotropy of the twin-roll-cast AZ31 sheet alloy.

Figure 3 shows the true stress-strain curves obtained under the same deformation conditions at $500^{\circ} \mathrm{C}$. It can be seen that each sample reached a steady state. The true stress values of TRC-AZ31 with different sampling directions and different accumulated plastic deformations during the steady stage at $500^{\circ} \mathrm{C}$ are summarized in Table 2 . It can be observed that the steady-state stress decreased with increasing temperature, from an average of $35 \mathrm{MPa}$ at $450^{\circ} \mathrm{C}$ to $28 \mathrm{MPa}$ at $500^{\circ} \mathrm{C}$. However, for a given deformation at $450^{\circ} \mathrm{C}$, the steadystate stress increased with the sampling direction, which differed from the trends observed for deformation at $500^{\circ} \mathrm{C}$. This may have resulted from the fact that as the temperature increases, activation of the nonbasal slip, such as prismatic $\langle a\rangle$ and pyramidal plane slip $\langle c+a\rangle$, is facilitated [16].

3.2. Microstructural Evolution. Figure 4 shows the initial longitudinal microstructure of the as-received TRC-AZ31 


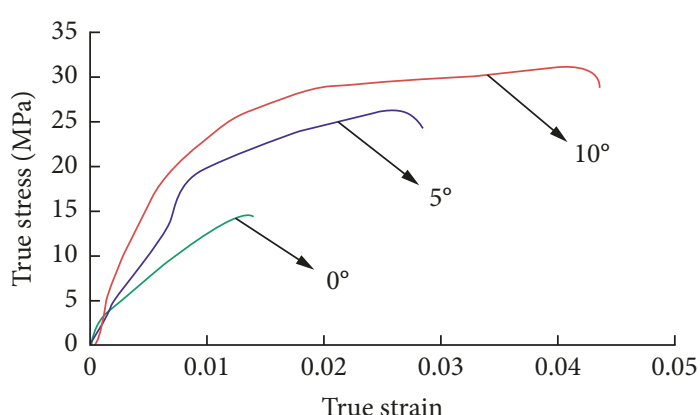

(a)

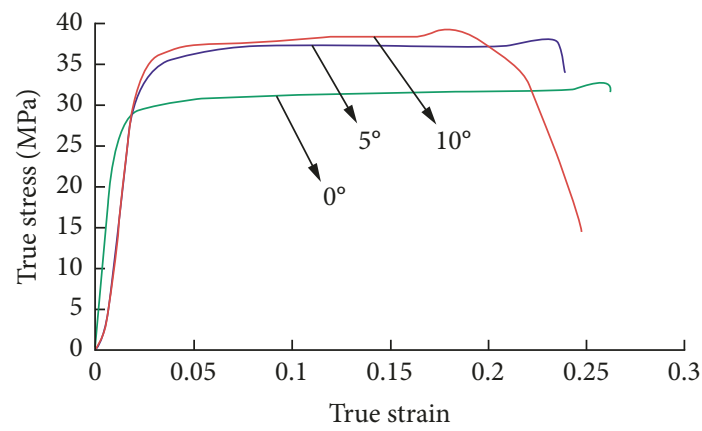

(c)

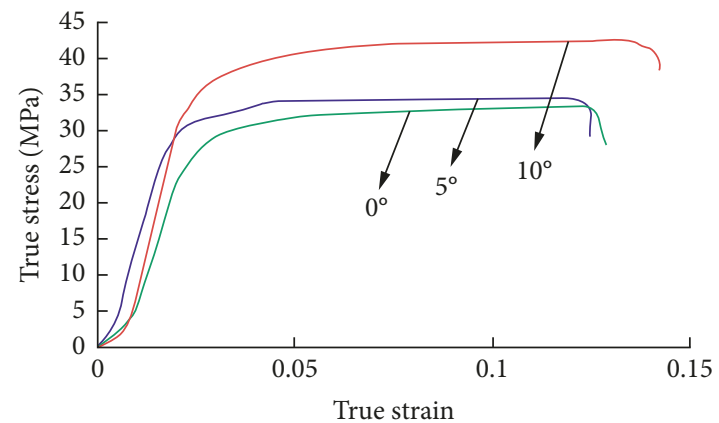

(b)

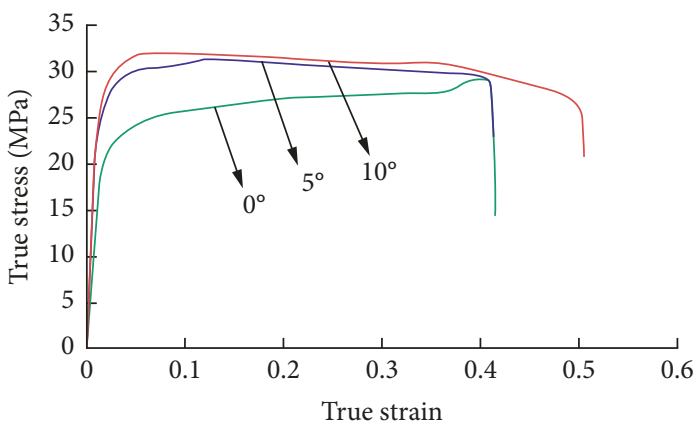

(d)

FIgURE 2: True stress-true strain curves of the TRC-AZ31 alloy during hot compression at $450^{\circ} \mathrm{C}$ : (a) $5 \%$ strain; (b) $15 \%$ strain; (c) $25 \%$ strain; (d) $35 \%$ strain.

TABle 1: True stress (MPa) of the TRC-AZ31 alloy during the stable stage at $450^{\circ} \mathrm{C}$.

\begin{tabular}{|c|c|c|c|}
\hline \multirow{2}{*}{ Strain (\%) } & \multicolumn{3}{|c|}{ Sampling direction } \\
\hline & $0^{\circ}$ & $5^{\circ}$ & $10^{\circ}$ \\
\hline 5 & - & - & 26 \\
\hline 15 & 28 & 34 & 40 \\
\hline 25 & 29 & 36 & 37 \\
\hline 35 & 29 & 31 & 33 \\
\hline
\end{tabular}

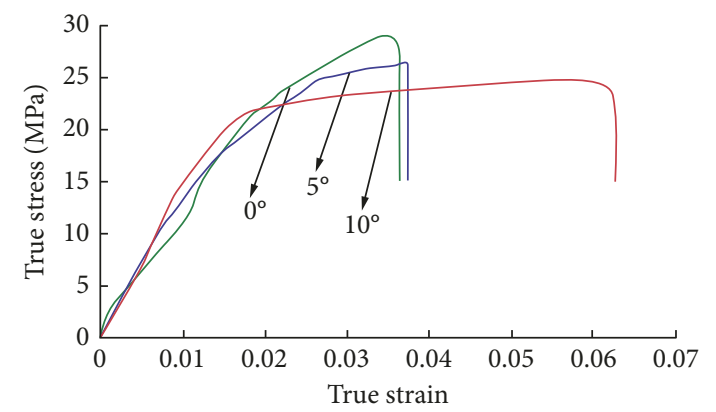

(a)

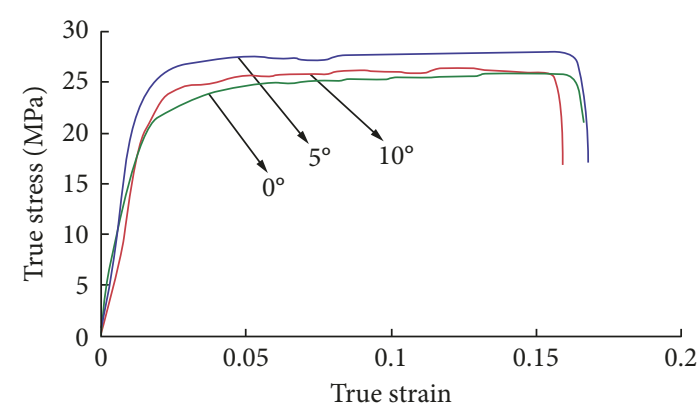

(b)

Figure 3: Continued. 


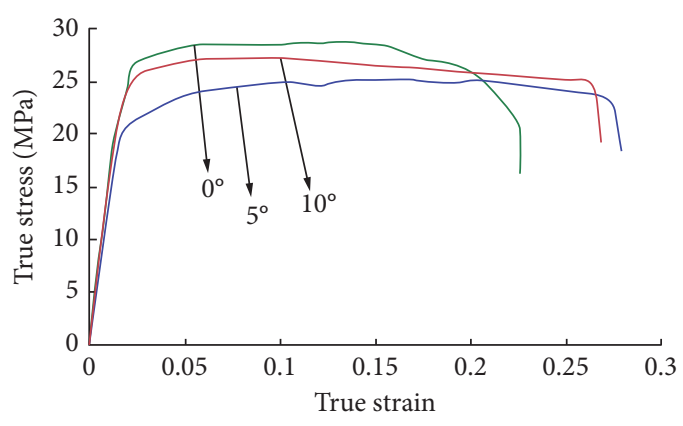

(c)

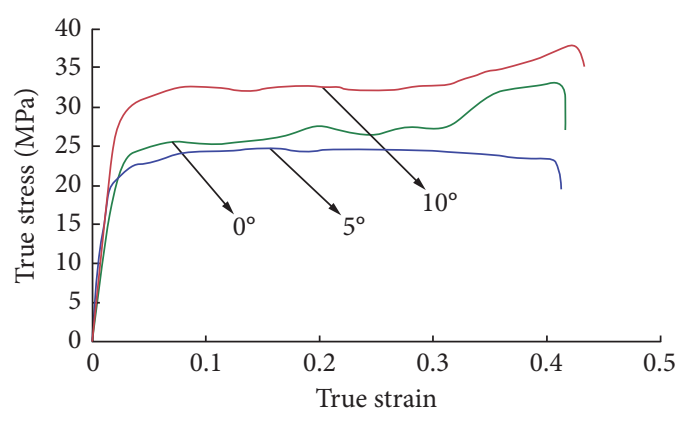

(d)

FIgURE 3: True stress-true strain curves of the TRC-AZ31 alloy during hot compression at $500^{\circ} \mathrm{C}$ : (a) $5 \%$ strain; (b) $15 \%$ strain; (c) $25 \%$ strain; (d) $35 \%$ strain.

TABle 2: True stress (MPa) of the TRC-AZ31 alloy during the stable stage at $500^{\circ} \mathrm{C}$.

\begin{tabular}{|c|c|c|c|}
\hline \multirow{2}{*}{ Strain (\%) } & \multicolumn{3}{|c|}{ Sampling direction } \\
\hline & $0^{\circ}$ & $5^{\circ}$ & $10^{\circ}$ \\
\hline 5 & 29 & 26 & 24 \\
\hline 15 & 25 & 27 & 26 \\
\hline 25 & 28 & 25 & 27 \\
\hline 35 & 27 & 24 & 33 \\
\hline
\end{tabular}

alloy. It can be observed that it consisted of dendritic columnar grains. Due to the high cooling rate and directional heat transfer during the TRC processes, large columnar grains have grown against the heat extraction direction, where the solidifying material has been in contact with the cold casting rolls.

Figure 5 reveals the microstructure after deformation at $450^{\circ} \mathrm{C}$ and strains ranging from $5 \%$ to $35 \%$ for sampling directions of $0^{\circ}, 5^{\circ}$, and $10^{\circ}$. In general, the dynamic recrystallization process is classified into continuous and discontinuous DRX [17]. Continuous recrystallization is considered a recovery process accompanied by a progressive increase in boundary misorientation and the conversion of low-angle boundaries into high-angle boundaries [18]. This type of recrystallization may be accompanied by gradual softening in the flow curve, resulting in a plateau in the true stress-true strain curves. As shown in Figure 5, for the $0^{\circ}$ sample with $5 \%$ strain, the necklace DRX grains are concentrated on grain boundaries due to the occurrence of nonbasal slip at high temperatures of $450^{\circ} \mathrm{C}$. This indicated DRX behavior depended on the temperature-dependent deformation mode. At $450^{\circ} \mathrm{C}$ and mainly low strains, microscopic strain localization at slip lines resulted in the formation of bulges at the grain boundaries, thereby leading to nucleation of DRX grains. At moderate and high strains, DRX occurred via nucleation in slip bands, and in both cases, rapid dislocation climb led to the formation of lowangle boundaries [19]. Moving dislocations are trapped by these sub-boundaries and are gradually converted into true high-angle boundaries. The results obtained for the AZ31 samples with $5^{\circ}$ and $15^{\circ}$ directions are similar to those obtained for the $0^{\circ}$ direction. High-temperature compression may be accompanied by dislocation annihilation and grain boundary migration. Moreover, grain rotation is easily activated at high temperature.

Figure 6 shows the microstructural evolution of the ascompressed samples at $500^{\circ} \mathrm{C}$. The nucleation of DRX grains is similar to that of $450^{\circ} \mathrm{C}$ compression. For the higher temperature, the degree of DRX was larger than the compression at $450^{\circ} \mathrm{C}$, which resulted in growth of the grains. Figure 7 shows the volume fraction of dynamically recrystallized grains (DRX-G). It was determined to quantify the effect of deformation temperature and the degree of deformation on the microstructure after hightemperature compression. It can be seen that the volume fraction of DRX-G increased with increasing level of deformation. This is typical of nucleation and growth type of transformations. During high-temperature compression, dislocation climb leads to the formation of low-angle boundaries. When the strain increases, moving dislocations are trapped by these sub-boundaries and are gradually converted into true high-angle boundaries. The volume fraction and size of dynamically recrystallized grains at $500^{\circ} \mathrm{C}$ were higher than the fraction and size associated with $450^{\circ} \mathrm{C}$ and the same deformation conditions. During hot compression, work hardening occurred in the newly formed recrystallized grains, and the size of these grains became limited as the driving force for further growth was reduced. As the temperature decreased, the level of work hardening increased, and the growth of the new grains was limited, thereby leading to a reduction in the DRX grain size. As shown in Figures 5 and 6, at low strain levels, the average grain size decreased with increasing strain. Once the dynamically recrystallized grains were established, the DRX grain size changed only slightly with increasing strain. 


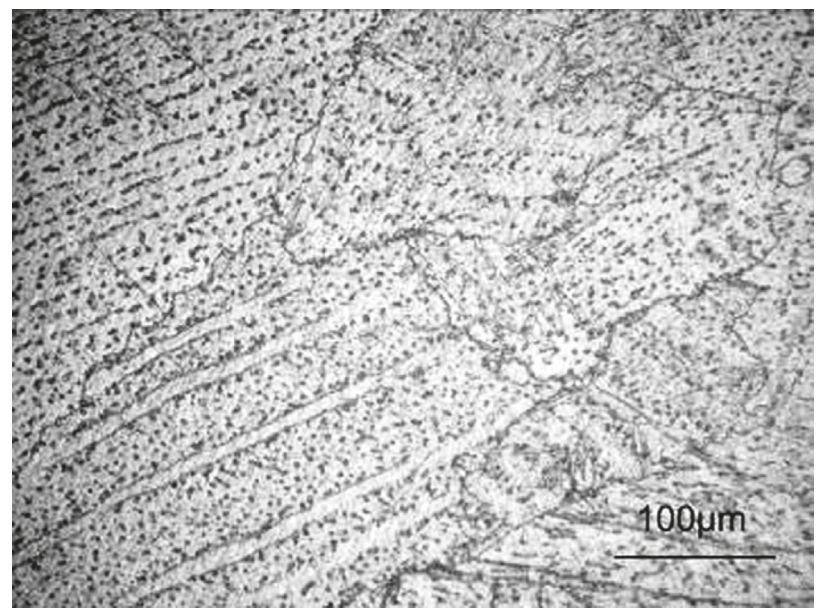

FIgUre 4: Optical micrograph of the TRC-AZ31 sheet alloy in the longitudinal orientation.
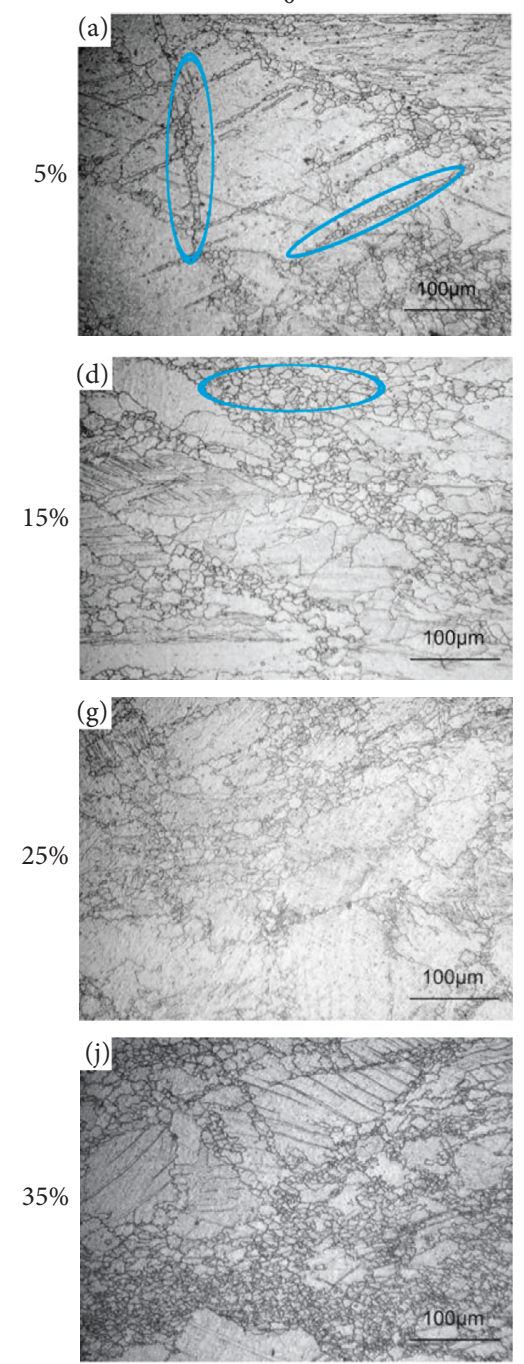

$5^{\circ}$
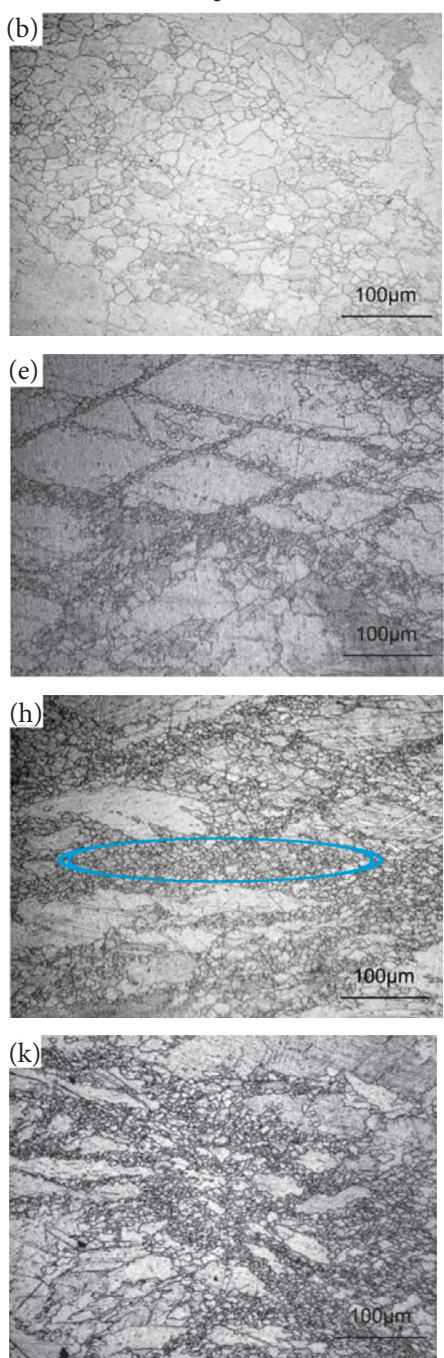

$10^{\circ}$
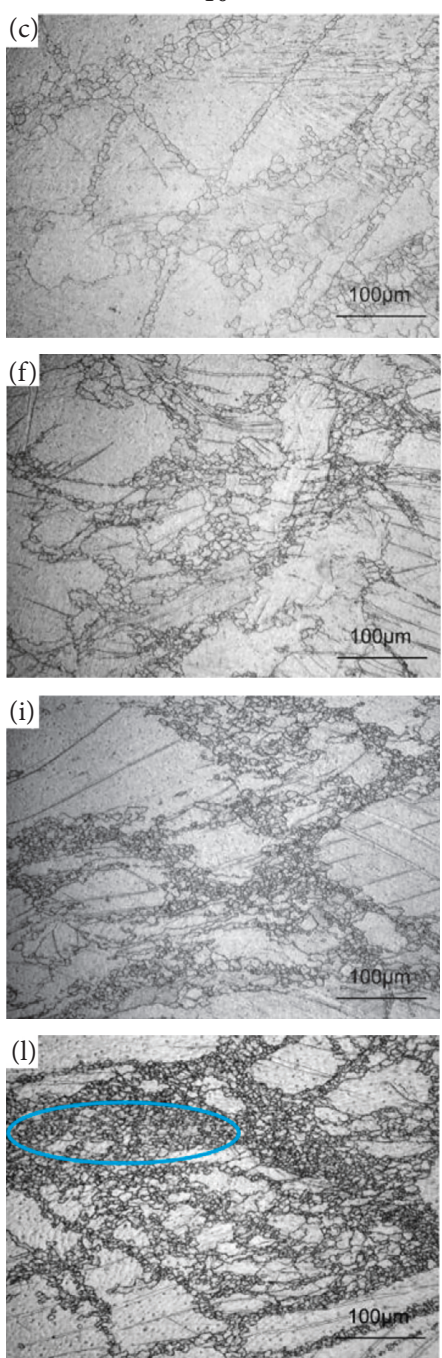

FIGURE 5: Microstructures of the twin-roll-cast (TRC) AZ31 alloy with different original sampling directions and different deformations under $450^{\circ} \mathrm{C}$ compression: (a) $0^{\circ}-5 \%$; (b) $5^{\circ}-5 \%$; (c) $10^{\circ}-5 \%$; (d) $0^{\circ}-15 \%$; (e) $5^{\circ}-15 \%$; (f) $10^{\circ}-15 \%$; (g) $0^{\circ}-25 \%$; (h) $5^{\circ}-25 \%$; (i) $10^{\circ}-25 \%$; (j) $0^{\circ}$ $35 \%$; (k) $5^{\circ}-35 \%$; (l) $10^{\circ}-35 \%$. 
$0^{\circ}$
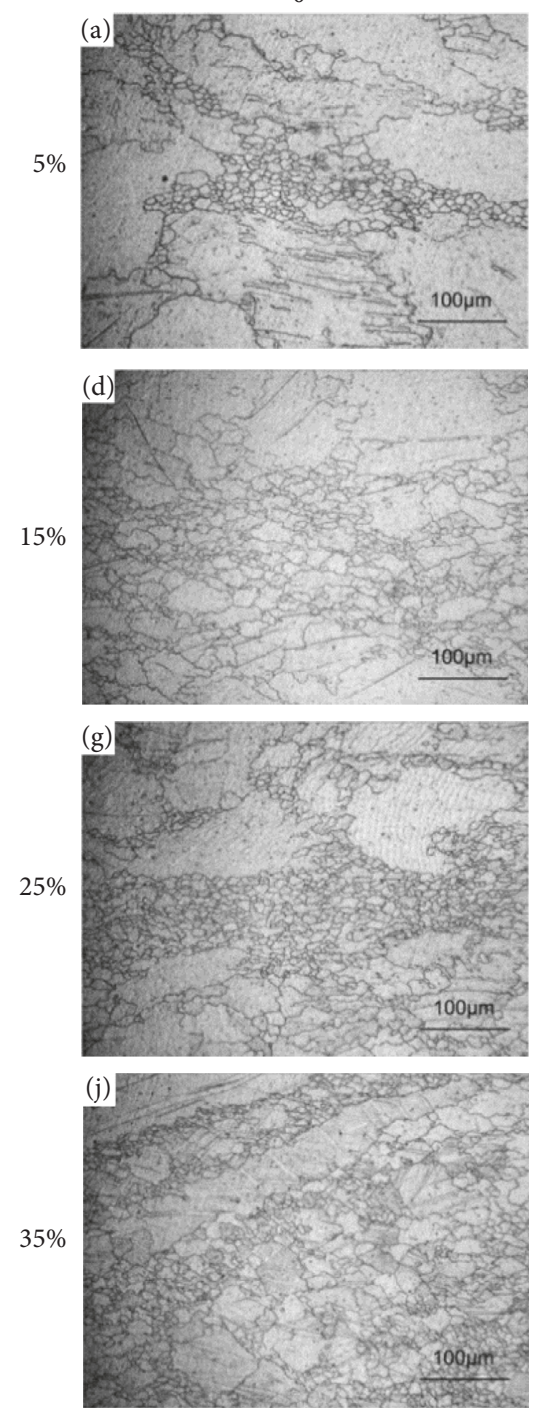

$5^{\circ}$
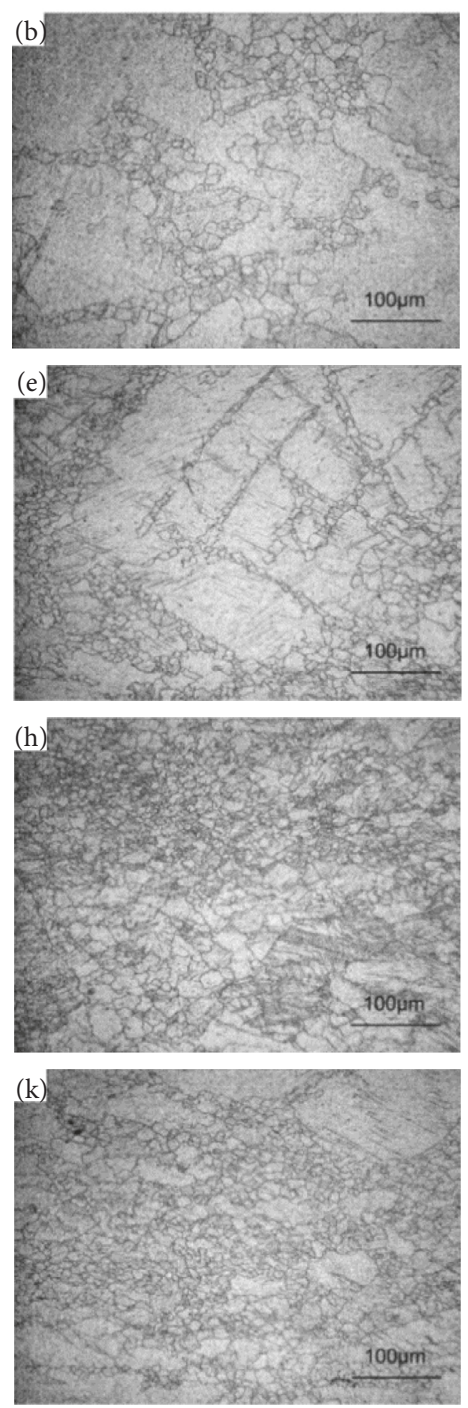

$10^{\circ}$
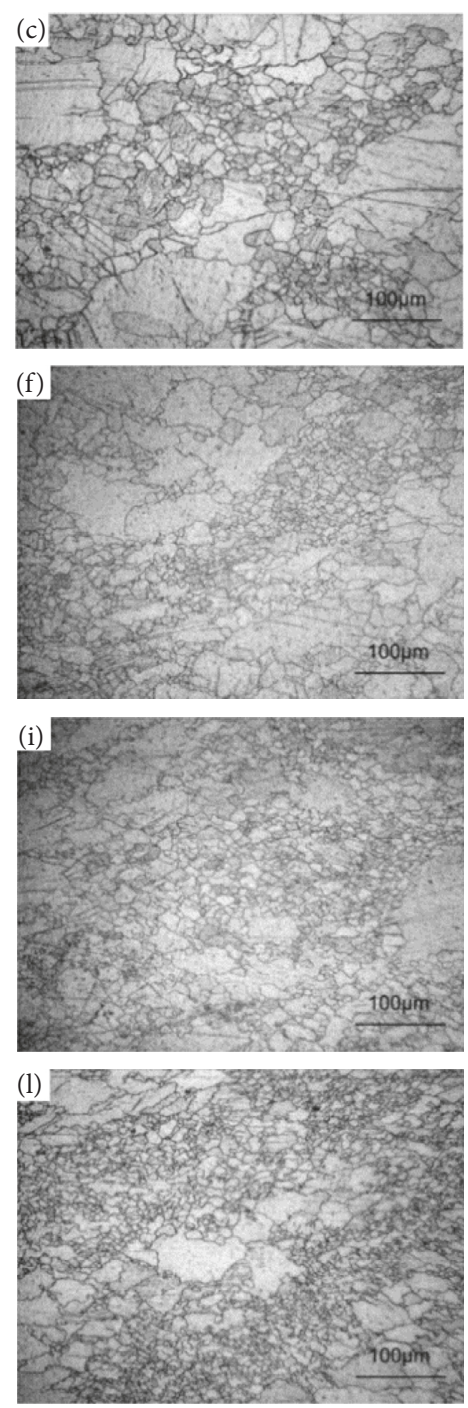

FIGURE 6: Microstructures of the twin-roll-cast (TRC) AZ31 alloy with different original sampling directions and different deformations at $500^{\circ} \mathrm{C}$ compression: (a) $0^{\circ}-5 \%$; (b) $5^{\circ}-5 \%$; (c) $10^{\circ}-5 \%$; (d) $0^{\circ}-15 \%$; (e) $5^{\circ}-15 \%$; (f) $10^{\circ}-15 \%$; (g) $0^{\circ}-25 \%$; (h) $5^{\circ}-25 \%$; (i) $10^{\circ}-25 \%$; (j) $0^{\circ}-35 \%$; (k) $5^{\circ}-35 \%$; (l) $10^{\circ}-35 \%$.

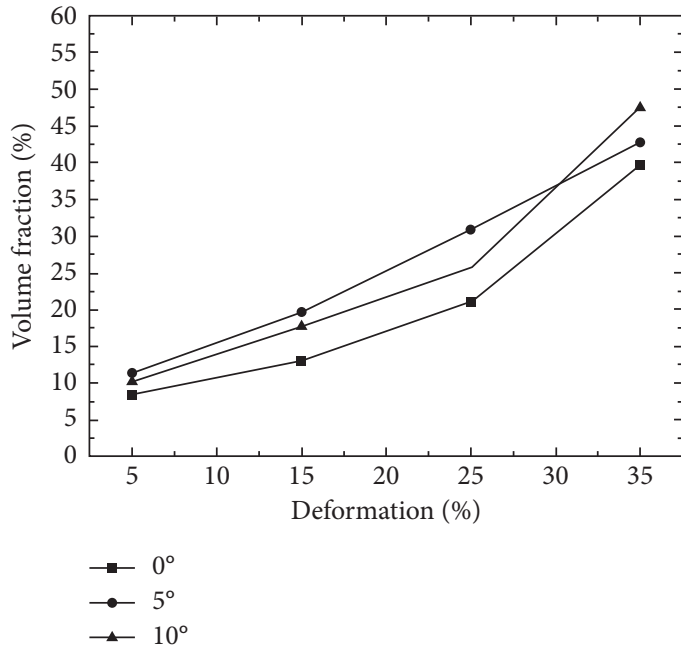

(a)

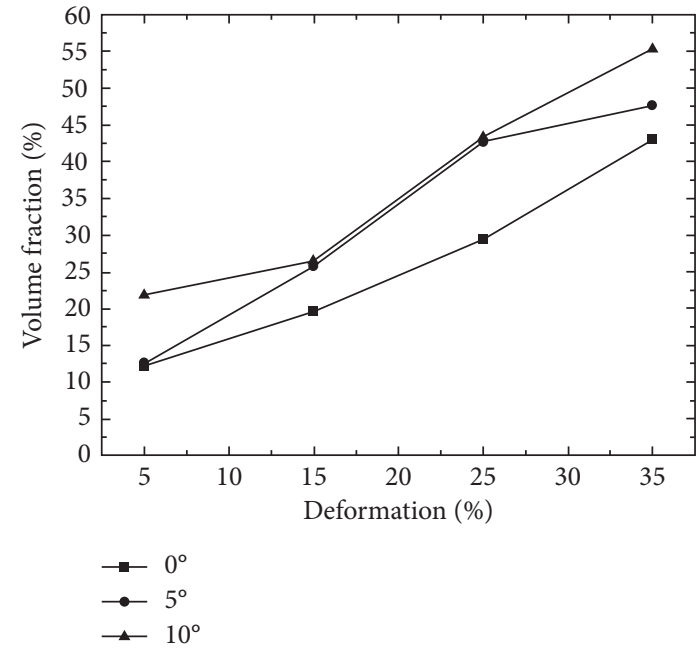

(b)

Figure 7: Volume fraction of dynamically recrystallized grains after hot deformation: (a) $450^{\circ} \mathrm{C}$; (b) $500^{\circ} \mathrm{C}$. 


\section{Conclusions}

The hot deformation behavior and microstructural evolution were investigated for twin-roll-cast AZ31 alloys subjected to compression strains at high temperatures and different sampling directions. In our present work, the conclusions can be mainly drawn as follows:

(1) The results revealed that the flow stress decreases with increasing temperature, from an average of $35 \mathrm{MPa}$ at $450^{\circ} \mathrm{C}$ to $28 \mathrm{MPa}$ at $500^{\circ} \mathrm{C}$

(2) The anisotropy of the flow stress associated with different sampling directions decreased with increasing temperature

(3) The volume fraction and grain size of the dynamically recrystallized grains increased when the deformation temperature increased from $450^{\circ} \mathrm{C}$ to $500^{\circ} \mathrm{C}$

\section{Data Availability}

All data included in this study are available upon request by contact with the corresponding author.

\section{Conflicts of Interest}

The authors declare that they have no conflicts of interest.

\section{Acknowledgments}

The authors are grateful for the financial supports from the National Natural Science Foundation of China (51701033 and 11847077), Chongqing Science and Technology Commission (cstc2018jcyjAX0022 and cstc2017jcyjAX0216), and Chongqing Municipal Education Commission (KJQN201901504, KJ1713336, and KJQN201801523).

\section{References}

[1] J. Zhang, S. Liu, R. Wu, L. Hou, and M. Zhang, "Recent developments in high-strength Mg-RE-based alloys: focusing on Mg-Gd and Mg-Y systems," Journal of Magnesium and Alloys, vol. 6, no. 3, pp. 277-291, 2018.

[2] T. Nakata, J. J. Bhattacharyya, S. R. Agnew, and S. Kamado, "Unexpected influence of prismatic plate-shaped precipitates on strengths and yield anisotropy in an extruded $\mathrm{Mg}-0.3 \mathrm{Ca}-$ 1.0In-0.1Al-0.2Mn (at.\%) alloy," Scripta Materialia, vol. 169, pp. 70-75, 2019.

[3] W. Liu, B. Jiang, J. T. QingshanYang, B. Liu, and F. Pan, "Effect of Ce addition on hot tearing behavior of AZ91 alloy," Progress in Natural Science: Materials International, vol. 29, no. 4, pp. 453-456, 2019.

[4] H. Pan, C. Yang, Y. Yang et al., "Ultra-fine grain size and exceptionally high strength in dilute $\mathrm{Mg}-\mathrm{Ca}$ alloys achieved by conventional one-step extrusion," Materials Letters, vol. 237, pp. 65-68, 2019.

[5] J. H. Kim, B.-C. Suh, T. T. T. Trang, Ji H. Hwang, and N. J. Kim, "Orientations of dynamically recrystallized grains nucleated at double twins in Mg-4Zn-1Sn alloy," Scripta Materialia, vol. 170, pp. 11-15, 2019.

[6] Q. Yang, Q. Dai, C. Lou et al., "Twinning, grain orientation, and texture variations in $\mathrm{Mg}$ alloy processed by pre-rolling,"
Progress in Natural Science: Materials International, vol. 29, no. 2, pp. 231-236, 2019.

[7] L. Wang, Z. Zhang, M. Cao et al., "Enhanced stretch formability of magnesium alloy sheet by prestretching at various speeds at higher temperature," JOM, vol. 71, no. 5, pp. 1705-1713, 2019.

[8] K. Wang, J. Wang, P. Xing et al., "Microstructure and mechanical properties of $\mathrm{Mg}-\mathrm{Gd}-\mathrm{Y}-\mathrm{Zn}-\mathrm{Mn}$ alloy sheets processed by large-strain high-efficiency rolling," Materials Science and Engineering: A, vol. 748, pp. 100-107, 2019.

[9] Q. Yang, H. Dong, J. Zhang, B. Jiang, and F. Pan, "Influence of pre-rolling on microstructural evolution of non-basal textured magnesium alloy," International Journal of Materials Research, vol. 110, no. 9, pp. 892-895, 2019.

[10] J. C. Tan and M. J. Tan, "Dynamic continuous recrystallization characteristics in two stage deformation of $\mathrm{Mg}-3 \mathrm{Al}-1 \mathrm{Zn}$ alloy sheet," Materials Science and Engineering A, vol. 339, no. 1-2, pp. 124-132, 2003.

[11] O. Sitdikov and R. Kaibyshev, "Dynamic recrystallization in pure magnesium," Materials Transactions, vol. 42, no. 9, pp. 1928-1937, 2001.

[12] M. R. Barnett, "Hot working microstructure map for magnesium AZ31," Materials Science Forum, vol. 426-432, no. 6, pp. 515-520, 2003.

[13] B. Jiang, W. Liu, Q. Dong, M.-X. Zhang, and F. Pan, "Grain refinement of $\mathrm{Ca}$ addition in a twin-roll-cast $\mathrm{Mg}-3 \mathrm{Al}-1 \mathrm{Zn}$ alloy," Materials Chemistry and Physics, vol. 133, no. 2-3, pp. 611-616, 2012.

[14] T. T. T. Trang, J. H. Zhang, J. H. Kim et al., "Designing a magnesium alloy with high strength and high formability," Nature Communications, vol. 9, no. 1, Article ID 2522, 2018.

[15] A. Chapuis and Q. Liu, "Modeling strain rate sensitivity and high temperature deformation of Mg-3Al-1Zn alloy," Journal of Magnesium and Alloys, vol. 7, no. 3, pp. 433-443, 2019.

[16] B. Jiang, W. Liu, S. Chen, Q. Yang, and F. Pan, "Mechanical properties and microstructure of as-extruded AZ31 Mg alloy at high temperatures," Materials Science and Engineering: A, vol. 530, pp. 51-56, 2011.

[17] W. J. Kim and T. J. Lee, "Two different types of deformation behaviors in ultrafine grained $\mathrm{Mg}$ alloys at high temperatures and development of the generalized constitutive equation for describing their deformation behavior," Materials Science and Engineering: A, vol. 613, pp. 264-273, 2014.

[18] F. Wang, R. Zheng, J. Chen et al., "Significant improvement in the strength of Mg-Al-Zn-Ca-Mn extruded alloy by tailoring the initial microstructure," Vacuum, vol. 161, pp. 429-433, 2019.

[19] A. Sankaran, S. Vadakke Madam, A. Nouri, and M. R. Barnett, "Attaining high compressive strains in pure $\mathrm{Mg}$ at room temperature by encasing with pure Al," Scripta Materialia, vol. 66 , no. 10, pp. 725-728, 2012. 


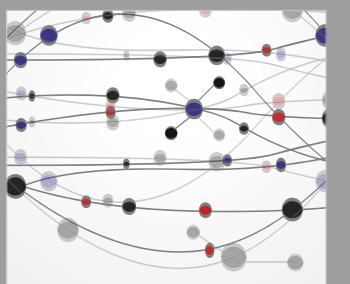

The Scientific World Journal
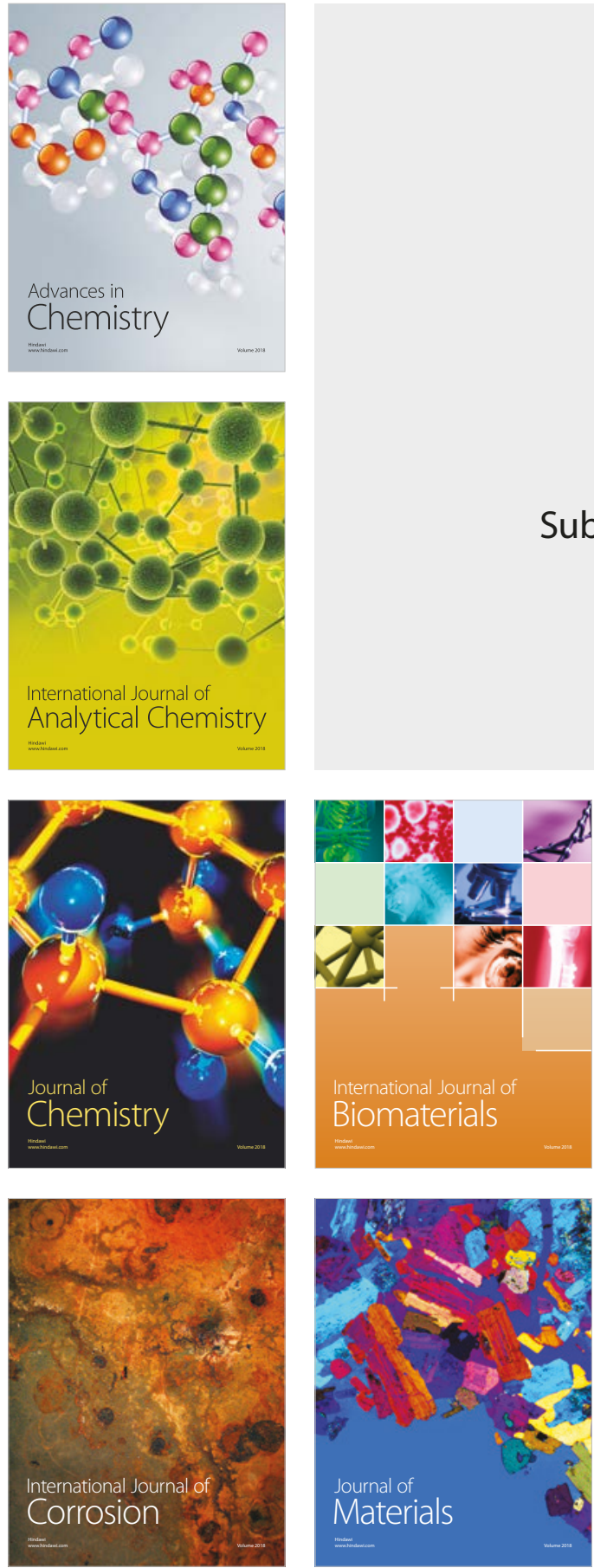

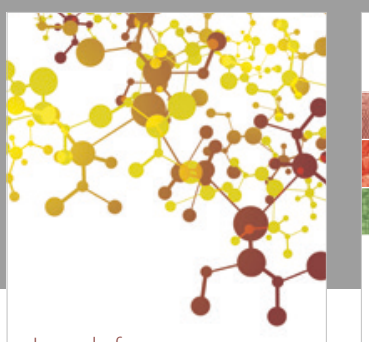

Journal of

Applied Chemistry
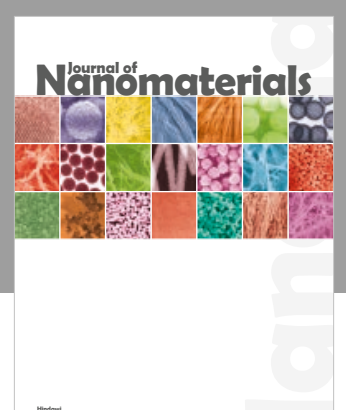

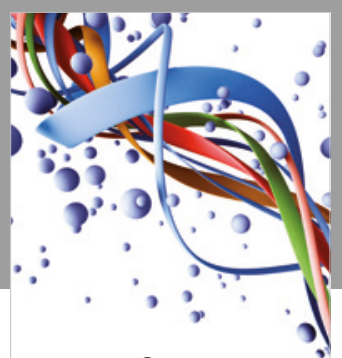

Scientifica

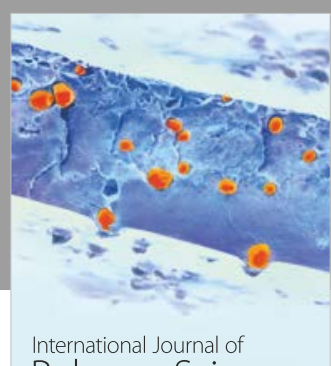

Polymer Science

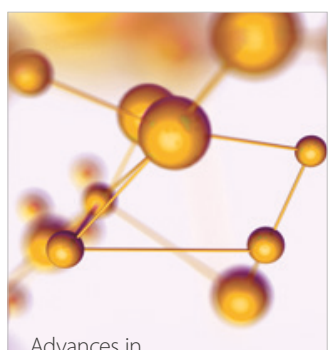

Physical Chemistry
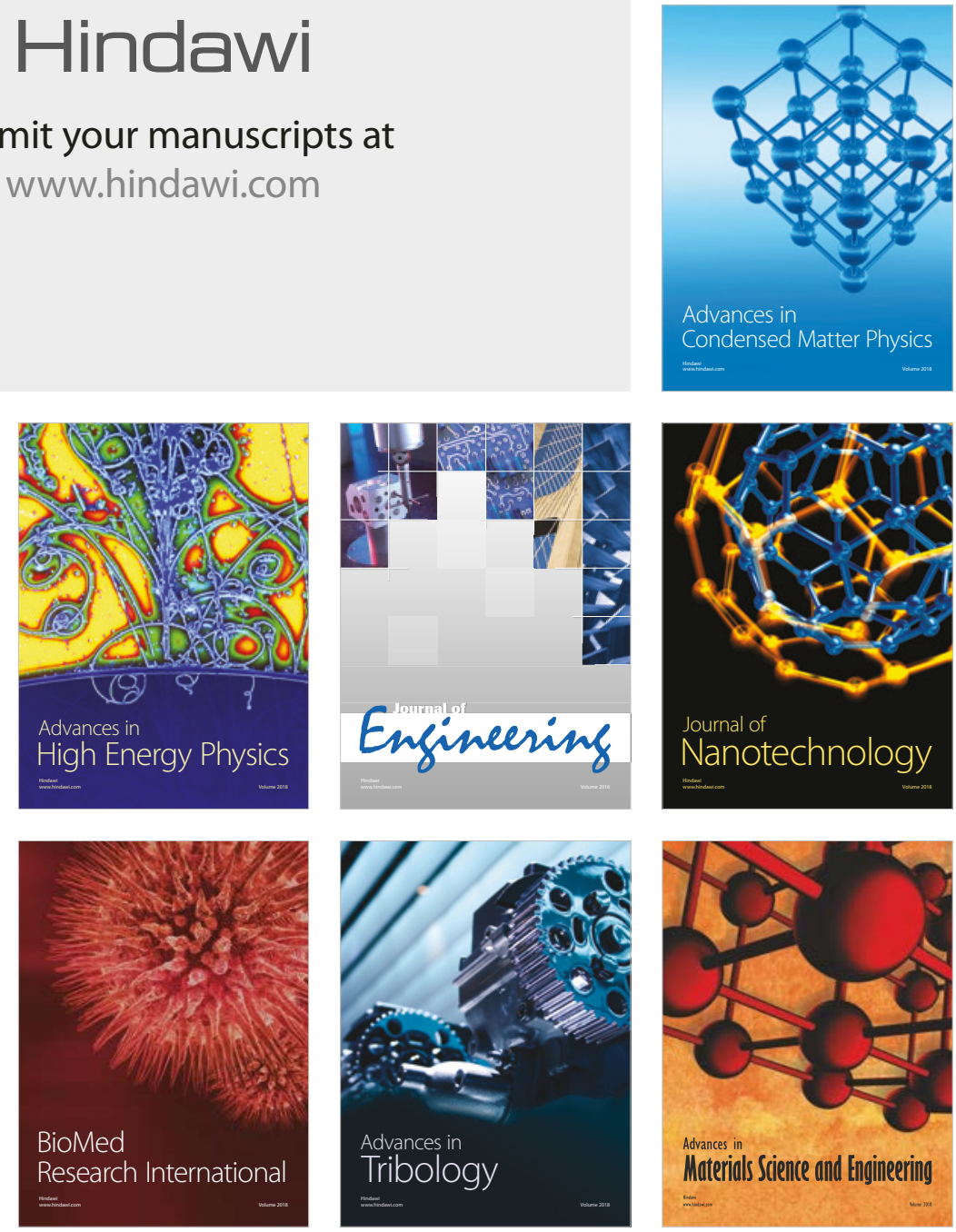